\title{
AROMA COMPOUNDS DERIVED FROM THE THERMAL DEGRADATION OF CAROTENOIDS IN A CASHEW APPLE JUICE MODEL
}

\author{
ZEPKA, L. Q. (1); DA SILVA, M.A.A.P. (2), GARRUTI, D. (3); \\ MERCADANTE, A. Z. (1)
}

(1) Departamento de Ciência de Alimentos, FEA-UNICAMP-Campinas, SP. Brasil. (2) Departamento de Alimentos e Nutrição, FEA-UNICAMPCampinas, SP. Brasil. (3) Embrapa Agroindustrial Tropical-Fortaleza, CE. Brasil. E-mail: zepkaleila@yahoo.com

In cashew apple juice, the fruit exotic aroma and flavor are amongst the most important attributes that can be altered during the beverage thermal treatment. In this research, the volatile compounds derived from the thermal degradation of carotenoids in a cashew apple juice model were studied as a function of temperature $\left(60\right.$ and $\left.90^{\circ} \mathrm{C}\right)$. The profile of volatile compounds was obtained by headspace-solid phase microextraction associated to gas chromatography coupled to flame ionization detector (HS-SPME-GC-FID) and further identified by a mass spectrometry detector (HS-SPME-GC-MS). High performance liquid chromatography coupled to photodiode array and mass spectrometry detectors (HPLCPDA-MS/MS) were used to establish the composition of carotenoids in the cashew apple juice model. More them 35 different volatiles were separated in the fresh cashew apple juice model; of which, at least 19 were generated as a consequence of heating the solution at 60 and $90^{\circ} \mathrm{C}$, such as: p-xylene, p-cresol, naphthalene, p-cymene, several methylundecane, dodecane, 1,2,3-methyl-benzene, and others. The volatiles $p$ xylene, $\mathrm{p}$-cresol, tridecane and o-propyltoluene were among the major compounds identified in the model solution heated at $60^{\circ} \mathrm{C}$. Some compounds, such as dimethyl-styrene, p-cymene, and p-xylene, were probably derived from the thermal degradation of the carotenoid polyene chain. On the other hand, $\beta$-ionone was not identified in the heated model solutions, although all-trans- $\beta$-cryptoxanthin and all-trans- $\beta$-carotene were found as the major carotenoids in heated cashew apple juice model. The volatiles formed in the model solutions as a consequence of carotenoids thermal degradation are likely to alter the cashew apple juice aroma and flavor.

Keywords: volatile compounds; cashew apple juice model; SPME-GC-MS Acknowledgements: The authors thank FAPESP for financial support. 